\title{
Erratum to: Leaf Removal Treatments Combined with Kaolin Particle Film Technique from Different Directions of Grapevine's Canopy Affect the Composition of Phytochemicals of cv. Muscat Hamburg ( $V$. Vinifera L.)
}

\author{
Demir Kok ${ }^{1} \cdot$ Erdinc Bal $^{1}$
}

Published online: 18 August 2017

(c) Springer-Verlag GmbH Deutschland 2017

\section{Erratum to:}

Erwerbs-Obstbau 2017

DOI 10.1007/s10341-017-0337-7

The original version of this article unfortunately contained errors in Figs. 1, 3, 4, 5, 6, 7 and 8. The corrected figures are given here.

The original article has been corrected.

The online version of the original article can be found under doi: 10.1007/s10341-017-0337-7

Demir Kok

dkok@nku.edu.tr

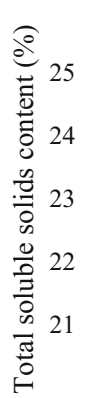

$\mathrm{LSD}_{\% 5}: 1.12$

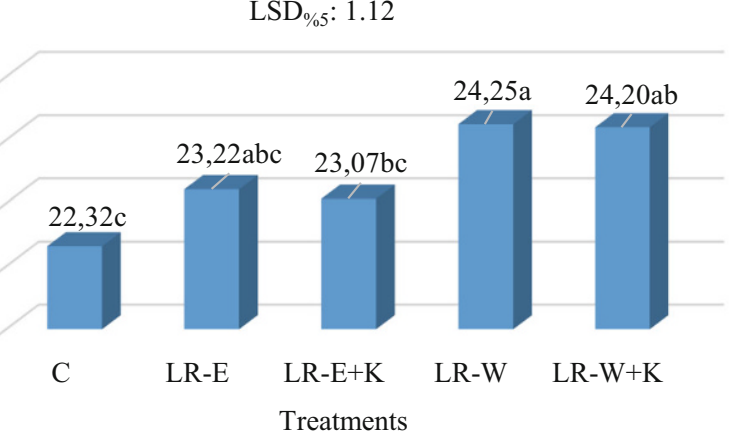

Fig. 1 Influences of different treatments on total soluble solids content

$\mathrm{LSD}_{\% 5}: 0.006$

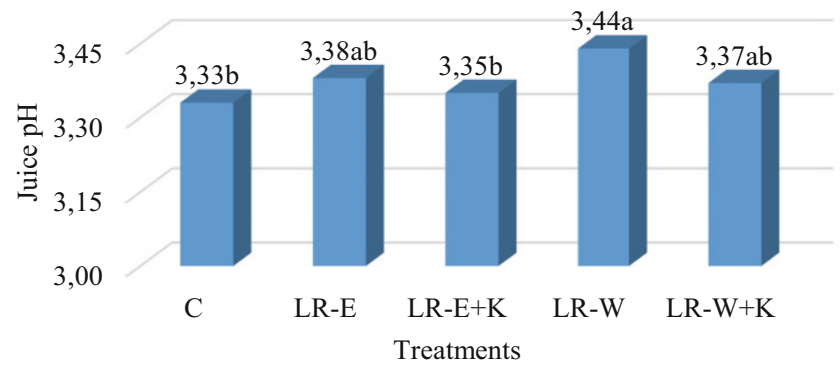

Fig. 3 Influences of different treatments on juice $\mathrm{pH}$

$\mathrm{LSD}_{\% 5}: 9.36$

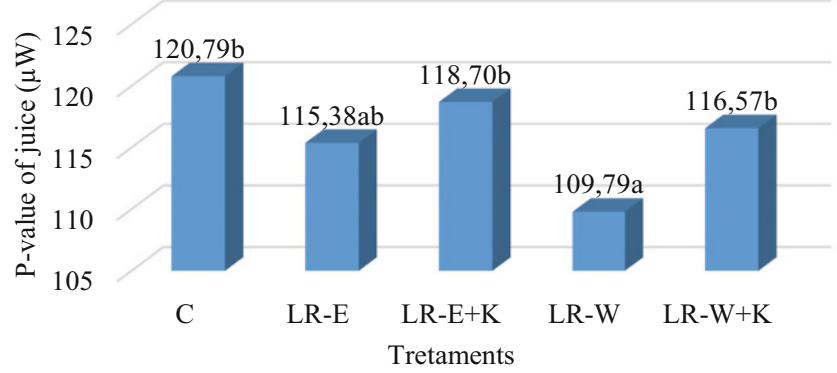

Fig. 4 Influences of different treatments on $p$-value of juice

Agricultural Faculty, Department of Horticulture, Namık Kemal University, 59030 Tekirdağ, Turkey 
$\mathrm{LSD}_{\% 5}: 93.48$

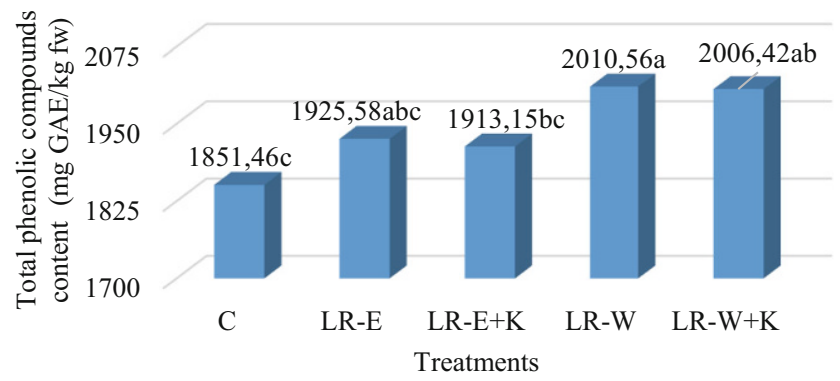

Fig. 5 Influences of different treatments on total phenolic compounds content

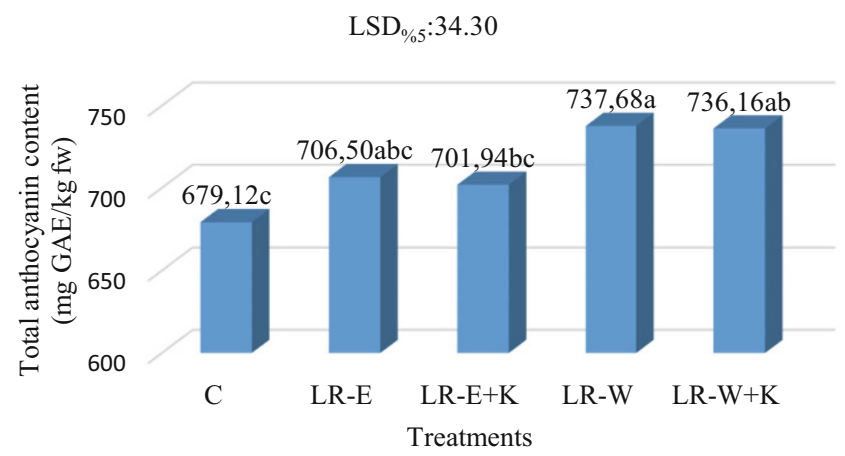

Fig. 6 Influences of different treatments on total anthocyanin content

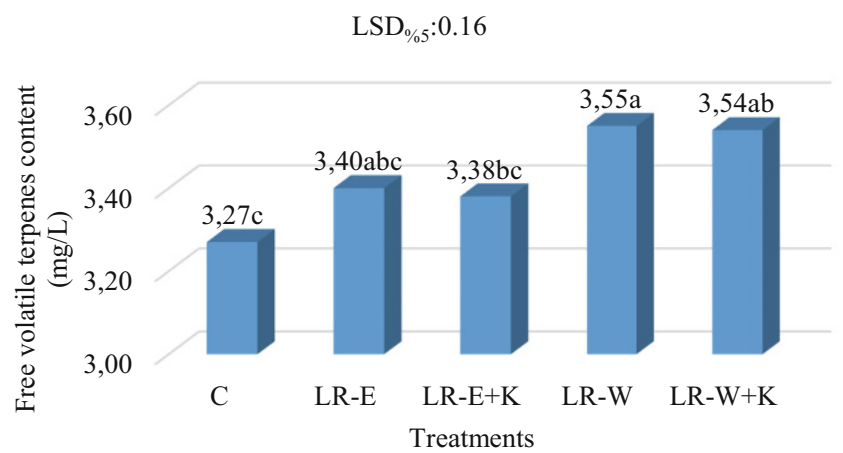

Fig. 7 Influences of different treatments on free volatile terpenes content

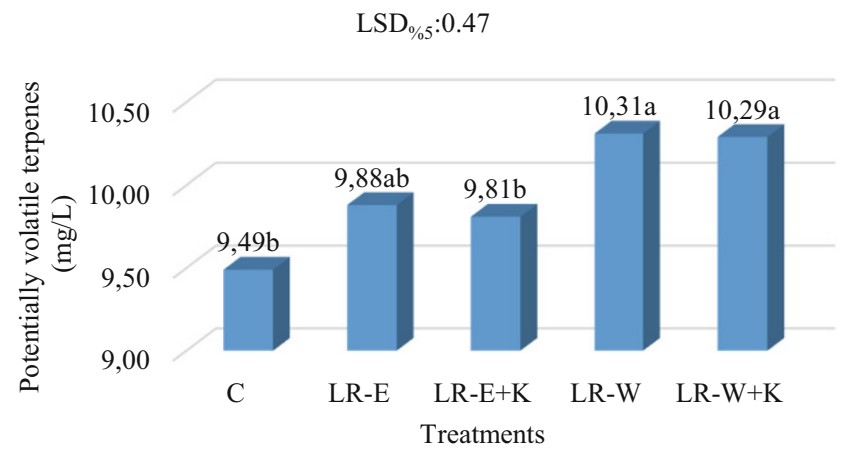

Fig. 8 Influences of different treatments on potentially volatile terpenes content 